\title{
Dried blood spots as a practical and inexpensive source for human immunodeficiency virus and hepatitis $C$ virus surveillance
}

\author{
Antonio Carlos de Castro Toledo Jr., José Nélio Januário*/**, \\ Renata Maria Silva Rezende**, Arminda Lúcia Siqueira***, Bernardo Freire de Mello**, \\ Érica Ligorio Fialho**, Raquel Andrade Ribeiro**, Hélia Lemos da Silva*, \\ Érika Carvalho Pires*, Taynaná César Simões***, Dirceu Bartolomeu Greco*/**/+
}

\author{
Serviço de Doenças Infecciosas, Faculdade de Medicina, Unifenas, Belo Horizonte, \\ MG, Brasil *Núcleo de Pesquisa em Apoio Diagnóstico **Departamento de Clínica Médica, Faculdade de Medicina \\ ****Departamento de Estatística, Universidade Federal de Minas Gerais, Av. Alfredo Balena 190, 30130-100 \\ Belo Horizonte, MG, Brasil
}

\begin{abstract}
Passive surveillance of infectious diseases with a high percentage of asymptomatic cases or long incubation periods, such as acquired immunodeficiency syndrome (AIDS), does not reflect the current transmission dynamics. Thus, a multi-strategic surveillance, such as the human immunodeficiency virus (HIV) sentinel surveillance proposed by the World Health Organization (WHO), is necessary. The Brazilian HIV sentinel surveillance was started in May 1992 with this purpose. The objectives of this study were to evaluate the feasibility and costs of HIV and hepatitis $C$ virus (HCV) surveillance using dried blood spots (DBS) collected for neonatal screening of metabolic diseases in the state of Minas Gerais, Brazil. This was accomplished through the comparison of HIV and HCV seroprevalence with previous Brazilian studies. From December 2001 to June 2002, 24,905 newborns were tested for HIV and 4211 for HCV. HIV seroprevalence was $0.25 \%$ and the $95 \%$ confidence interval (CI) was $0.18,0.31 \%$; and $\mathrm{HCV}$ seroprevalence was $0.71 \%$ and the $95 \%$ CI was $0.46,0.97 \%$. These numbers are similar to previous Brazilian studies. Cost in this study was approximately US\$3.10 per sample, which was roughly one third of the cost of the same exam at the Brazilian HIV sentinel surveillance. We conclude that it is possible and more cost-effective to use DBS for infectious diseases surveillance, albeit it is still necessary to compare these results with the usual sentinel methodology in a concomitant trial.
\end{abstract}

Key words: human immunodeficiency virus seroprevalence - hepatitis C - sentinel surveillance - infectious disease

Passive surveillance of infectious diseases with a high percentage of asymptomatic cases or long incubation periods does not reflect the actual epidemiological status of the disease. In diseases with long incubation periods such as acquired immunodeficiency syndrome (AIDS) and chronic viral hepatitis, passive case report does not depicts the current infection dynamics (Alary \& Castel 1990). Thus, a prolonged multi-strategic surveillance system is necessary to get a reliable idea of disease trends. The World Health Organization (WHO) recommends that human immunodeficiency virus (HIV) surveillance should be done trough periodical prevalence studies in a specific population. An isolated prevalence study will reveal HIV status in that population at a single moment, but the evaluation of serial prevalence studies can indicate the epidemics trend (WHO 1992). This strategy is known as sentinel surveillance and can be applied to different population settings [such as in-hospital patients, emergency care, sexually transmitted diseases (STD) clinics, antenatal or neonatal services] and for different diseases with similar patterns, such as HIV, hepatitis B and C (Dondero et al.

${ }^{+}$Corresponding author. E-mail: greco@medicina.ufmg.br Received 25 January 2005

Accepted 1 June 2005
1988, Matuszak et al. 1990, McLaws et al. 1990, Pappaioanou et al. 1990, Gwinn et al. 1991, Tappin et al. 1991, 1998, Borgdorff et al. 1993, Kigadye et al. 1993, Alary et al. 1994, Canosa et al. 1997, Siedler et al. 1998, Amar et al. 1999).

The Brazilian HIV Sentinel Surveillance Project started in May 1992, and since 1997 it is being performed in STD clinics, emergency care units, and with intravenous drug users, and childbearing women with a convenience sample. In 2000, a new random sampling strategy was adopted for childbearing women looking for more representative data. Cluster sampling method was established with two phases, starting with the selection of cities throughout the country and then selecting hospitals with at least 1000 childbirths per year in these cities. One hundred and fifty hospitals were randomly selected to have 120 samples each. Detailed discussion of this methodology has been published elsewhere (Szwarcwald \& Carvalho 2000).

The state of Minas Gerais, Brazil, has a well established Neonatal Screening Programme (NSP) covering all municipalities and $96 \%$ of newborns, with approximately 24,000 children screened per month (Serjeant 2000). Blood samples from heel sticks are collected in filter paper after the fifth day of birth and sent to a Central Laboratory (Núcleo de Pesquisa em Apoio Diagnóstico - Nupad) at the Federal University of Minas Gerais by regular mail. The samples are tested for sickle cell anemia, congenital 
hypothyroidism, cystic fibrosis and phenylketonuria and the results are available 14 days after blood collection. Many other tests can be done with dried blood spots (DBS) (Aebischer et al. 1990), including serologic and molecular tests for HIV, hepatitis B virus, and hepatitis C virus (Gascon et al. 1988, Varnier et al. 1988, Cassol et al. 1991, 1992, Gupta et al. 1992, Nyambi et al. 1994, Comeau et al. 1996, Biggar et al. 1997, Tappin et al. 1998, Panteleeff et al. 1999, Parker et al. 1999, Singh et al. 2000, Proietti et al. 2001, Rollins et al. 2002). DBS tests for infectious diseases have been already validated and have shown good correlation with traditional serological tests (Parry et al. 1992, Pappaioanou et al. 1993, Beck et al. 2001). Newborns start to produce their own antibodies by the second month of age and the antibodies identified shortly after birth are usually maternal. Thus, it is possible to estimate the seroprevalence of infectious diseases among childbearing women by testing their newborn blood for antibodies.

Sentinel evaluations are crucial for public health decisions, but they are also very expensive and complex to implement. The use of an established NSP for this purpose can be simpler, cheaper, and more feasible than traditional methods.

The objectives of this study were to evaluate the feasibility and costs of infectious disease surveillance using dried blood spots collected for neonatal screening of metabolic diseases in the state of Minas Gerais, Brazil. This was accomplished through the comparison of HIV and HCV seroprevalence with previous Brazilian studies.

\section{METHODS}

Population - This was a transversal study in newborns from Minas Gerais who were included in NSP between December 2001 and June 2002. The NSP form included the date of collection and city of birth; mother age was not available. All tests were performed anonymously and unlinked. The project is in accordance with the Declaration of Helsinki (2000) and was approved by the Federal University of Minas Gerais Research Ethics Committee.

Sample-size - The Brazilian 2000 HIV Sentinel Surveillance found a national mean for HIV seroprevalence among childbearing women of $0.47 \%$, with a $95 \%$ confidence interval (CI) of 0.362, 0.576 (Szwarcwald \& Carvalho 2000). Focaccia et al. (1998) observed a mean HCV prevalence of $1.5 \%$ in São Paulo metropolitan area in 1997. Based on theses two studies, the sample size was calculated according to statistical criteria for the prevalence estimation, namely an acceptable error at the 95\% CI (Lemeshow et al. 1990, Rosner 1995), and tests costs using nQuery Advisor $4.0^{\circledR}$ software. Sample size for HIV were calculated to be representative for Minas Gerais micro-regions and considered the estimated number of children born in one month (approximately 24,000). For HCV, a representative sample for micro-regions was calculated and comprised 4200 children ( $95 \%$ confidence level, maximum error 0,014$)$. Each one of the 66 micro-regions was considered a stratum and a stratified sample was calculated according to the number of screened children in each one. Cities with no data were excluded. The means of screened children were calculated according to NSP registers from January to August 2001.

Data collection and analysis - All tests for DBS were done at Nupad using Umelisa HIV 1+2 Recombinant Test and Umelisa HCV Test (Tecnosuma International, La Habana, Cuba), registered at Brazilian Ministry of Health. This HIV test has been already validated and used in a study of HIV prevalence among intravenous drug users by the Brazilian AIDS Programme (Proietti et al. 2001). The $\mathrm{HCV}$ test, as far as we know, is yet to be validated in Brazil. All samples were tested for HIV $(1+2)$ and HCV antibodies detection and the positive samples were re-tested with the same kit. Confirmatory tests for DBS were not available at this time. Afterwards, the whole consolidated results and tests costs were compared with the Brazilian Ministry of Health's 2000 Sentinel Study.

\section{RESULTS}

From the 24,905 ELISA tests for HIV-1+2, 61 were positive and seven borderline. For HCV, 4211 tests were done, 30 were positive and four borderline. Borderline results were discarded at analysis and micro-regions were grouped in 26 macro-regions. HIV seroprevalence varied from zero (observed in six macro-regions) to $0.81 \%$ with a mean of $0.25 \%$ and a $95 \%$ CI of $0.18,0.31 \%$. HCV seroprevalence varied from zero (observed in 11 macro-regions) to $2.86 \%$ with a mean of $0.71 \%$ and a $95 \%$ CI of $0.46,0.97 \%$. From a total of 26 macro-regions, 20 had at least one HIV positive test and 15 had at least one HCV positive test (Table I). Figs 1 and 2 show the spatial distribution of HIV and HCV seroprevalence, respectively. Spatial distribution analysis showed higher seroprevalence of both HIV and HCV in macro-regions with known high injectable drug use, especially Uberlandia, Uberaba, and Passos or crossed by important interstate highways, as Itabira, Coronel Fabriciano, Governador Valadares, and Teofilo Otoni.

\section{TABLE I}

Human immunodeficiency virus (HIV) and hepatitis C virus (HCV) seroprevalence from blood samples of newborns in Minas Gerais, Brazil, 2002

\begin{tabular}{|c|c|c|c|c|c|}
\hline Agent & $\begin{array}{c}\mathrm{Nr} \\
\text { subjetcs }\end{array}$ & $\begin{array}{c}\text { Lower } \\
\text { prevalence }\end{array}$ & $\begin{array}{c}\text { Higher } \\
\text { prevalence } \\
(\%)\end{array}$ & $\begin{array}{c}\text { Mean } \\
(\%)\end{array}$ & $\begin{array}{c}95 \% \mathrm{CI} \\
(\%)\end{array}$ \\
\hline HIV & 24,898 & Zero $^{a}$ & 0.81 & 0.25 & $(0.18,0.31)$ \\
\hline $\mathrm{HCV}$ & 4,907 & Zero $^{b}$ & 2.86 & 0.71 & $(0.46,0.97)$ \\
\hline
\end{tabular}

$a$ : six out of $26 ; b$ : 11 out of 26 ; CI: confidence interval

\section{DISCUSSION}

Seroprevalence of HIV and HCV - There are few large studies on HIV and HCV seroprevalence in Brazil. One of them, the Brazilian 2000 HIV Sentinel Surveillance found a mean HIV seroprevalence among childbearing women of $0.47 \%$ and a $95 \% \mathrm{CI}$ of $0.362,0.576$ for the country (Szwarcwald \& Carvalho 2000). For HCV infection, the largest population-based seroprevalence study based on 1059 persons was performed by Focaccia et al. (1998) in São Paulo metropolitan area, showing a seroprevalence 


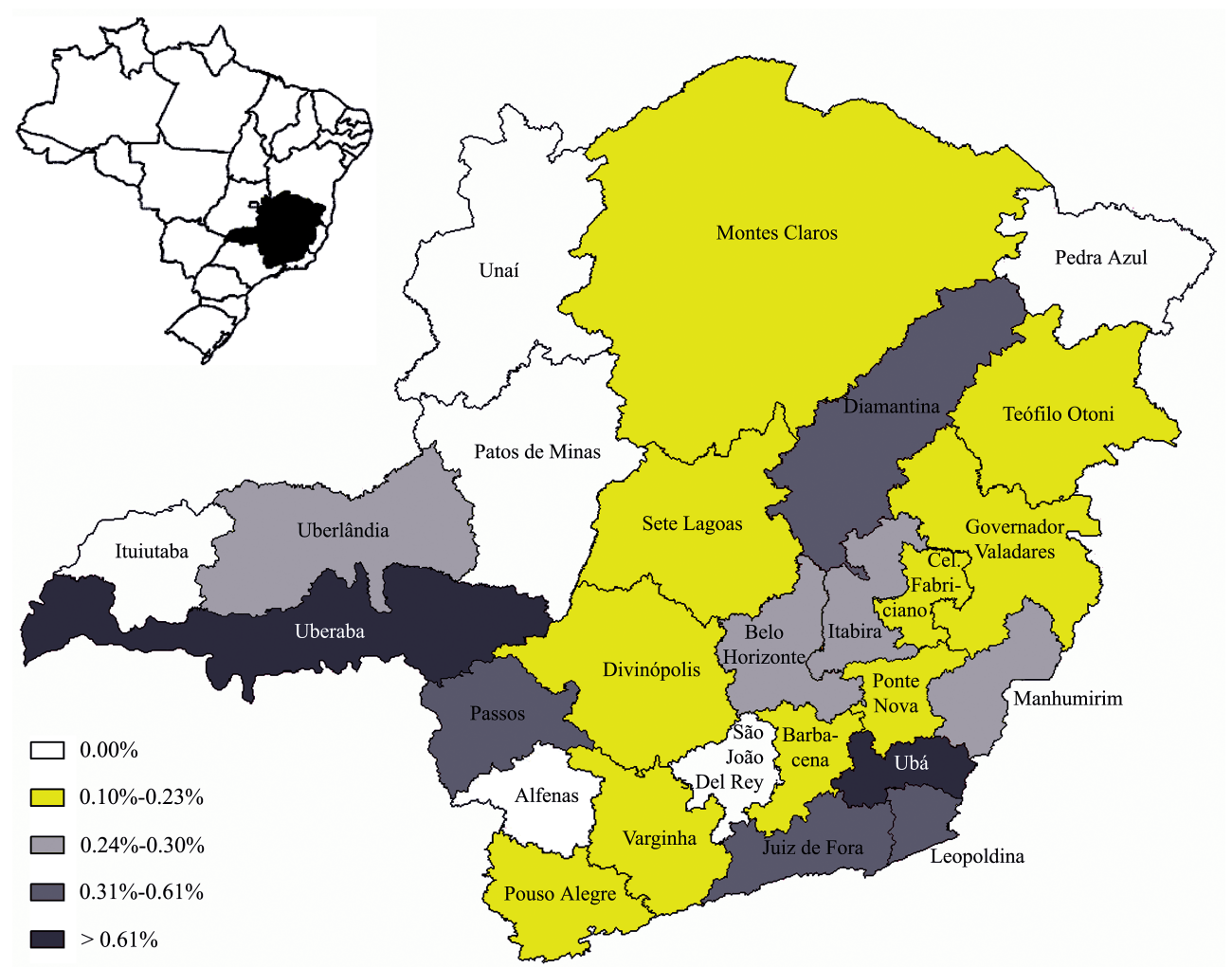

Fig 1: spatial distribution of human immunodeficiency virus seroprevalence in blood samples of newborns in the 26 macro-regions of Minas Gerais, Brazil, 2002.

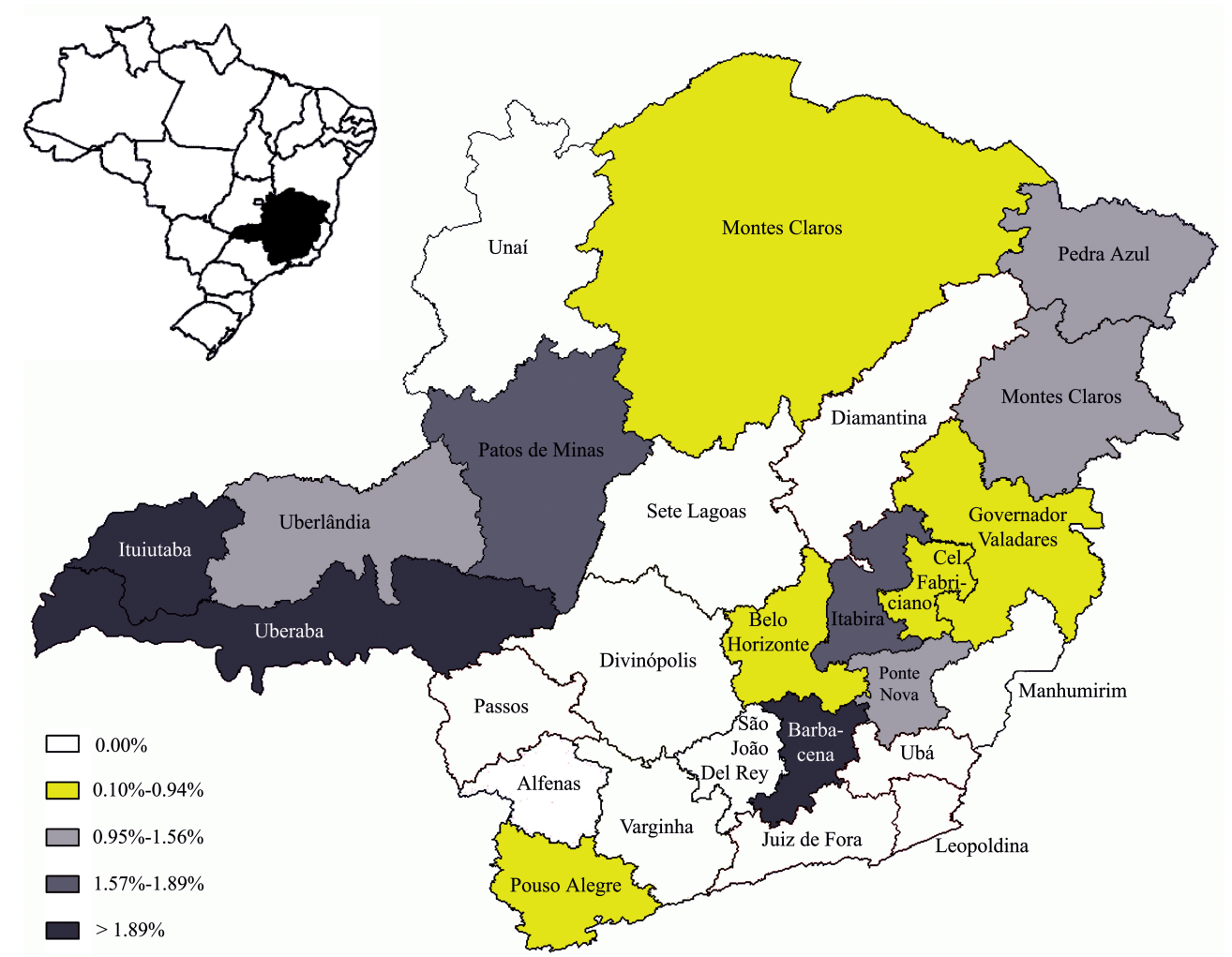

Fig. 2: spatial distribution of hepatitis C virus seroprevalence in blood samples of newborns in the 26 macro-regions of Minas Gerais, Brazil, 2002 . 
ranging from 0 to $3.25 \%$ among persons between $15-49$ years of age (Table II), with no statistical differences between male and female.

Despite the apparent differences in the means, our results are practically very similar to the above-mentioned studies, when considering the confidence intervals (Table III). On the other hand, these studies are probably not comparable as their population and sampling method were different and were done in different times. Concerning HIV, we evaluated regionally the same population (childbearing women) but two years later than the Ministry of Health study (Szwarcwald \& Carvalho 2000), which represents the national seroprevalence. In relation to Focaccia et al. (1998) HCV seroprevalence study, there is a fiveyear gap and their data represent both male and female from São Paulo metropolitan area.

There was a wide variation in HIV and HCV prevalence among Minas Gerais macro-regions, as depicted in Figs 1 and 2. HIV is not only more disseminated throughout the state but it is still spreading centrifugally from large to small towns, mainly due to unprotected sexual contact and had a more pronounced variation than HCV. Nevertheless there was an overlapping of high prevalence areas in Western, Central, and Northeastern regions. Those differences in prevalence maybe due to a later introduction of HCV among the population evaluated, and to differences in the transmission mode of the virus. As intravenous drug use is currently considered the main transmission mode of HCV this characteristic could limit its dissemination to regions where these drugs are more easily available. It is thus remarkable that the prevalence for HCV was still higher than for HIV, as showed in other studies.

Feasibility and costs - The total cost for the 2003 Brazilian HIV Sentinel Surveillance was estimated at US\$ $280,000.00$ or US\$ 8.5 per sample tested for HIV, HBV, HCV, and syphilis. About $45 \%$ of this cost was for local personal training and wages; $20 \%$ for laboratorial supplies (tubes, vacutainers, and needles); samples and labora- tory supplies transportation; and $35 \%$ for the serologic kits. Our study had a total cost of R \$30,600.00 or US\$1.27 per sample tested for HIV and HCV. If all serological tests are included, as in Brazilian Sentinel Surveillance Program, our cost per sample would be US\$ $3.10,36.5 \%$ of the Brazilian Program. The NSP-based surveillance has practically no extra costs with personal training and wages, laboratory supplies and sample transportation. As the infrastructure is already set, the only additional costs are testing expenses (kits plus laboratory time) and data analyses, making the procedure considerably cheaper and practical. DBS may be also useful for epidemiological studies in other populations and/or for diagnosis purposes in remote areas, avoiding the technical hurdles. Of course in this situation the actual cost per sample will be higher than in places with an already established NSP, but probably worth considering as it would avoid the expenses and hurdles related to drawing, stocking, and transporting blood samples.

It must also be emphasized that NSP is not appropriate for routine HIV infection diagnosis among childbearing women as it would be unethical to have this diagnosis only after birth. In this case, it makes more sense to increase efforts to have HIV tests available early in pregnancy, as is the Brazilian Ministry of Health policy.

Sampling strategy in the usual sentinel study is quite different from NSP-based studies. Sentinel study uses cluster sampling, which has a higher risk of selection bias. As the Brazilian Sentinel Program defines hospitals as sample unit, the chances of selecting a hospital that is a reference for HIV-infected childbearing women is not small, consequently overestimating HIV seroprelavence. NSP sampling is easier to perform and has a higher chance of being representative of the target population, as it is a simple random sampling. On the other hand, NSP needs a prior existing structure and a good coverage of population to be representative. Another drawback is that if maternal antibodies levels in newborn blood are very low there will be a chance of false-negative tests, which would underestimate the seroprevalence.

TABLE II

Hepatitis C virus seroprevalence in adults (15 to 49 years) in the metropolitan area of São Paulo, Brazil, 1997

\begin{tabular}{lcccr}
\hline Age & $15-17$ years & $18-29$ years & $30-39$ years & $40-49$ years \\
\hline Prevalence & 0.00 & 0.00 & 2.21 & 3.25 \\
$95 \%$ CI & $(0.000,2.770)$ & $(0.000,2.770)$ & $(0.050,4.320)$ & $(0.007,6.430)$ \\
\hline
\end{tabular}

CI: confidence interval

TABLE III

Major human immunodeficiency virus and hepatitis C virus seroprevalence studies in Brazil from 1997 to 2002

\begin{tabular}{|c|c|c|c|c|c|c|c|}
\hline \multirow{4}{*}{$\frac{\text { Study }}{\text { Present work }}$} & \multirow{4}{*}{$\begin{array}{r}\text { Year } \\
2002\end{array}$} & & & \multicolumn{2}{|c|}{ HIV } & \multicolumn{2}{|c|}{$\mathrm{HCV}$} \\
\hline & & \multicolumn{2}{|c|}{ Nr subjects } & Mean $(\%)$ & $95 \%$ CI (\%) & Mean $(\%)$ & CI $95 \%(\%)$ \\
\hline & & HIV & 24,898 & 0.25 & $(0.18,0.31)$ & - & - \\
\hline & & $\mathrm{HCV}$ & 4,907 & - & - & 0.71 & $(0.46,0.97)$ \\
\hline Szwarcwald (2000) & 2000 & & 15,426 & 0.47 & $(0.36,0.58)$ & - & - \\
\hline Focaccia et al. (1998) & 1997 & & 719 & - & - & $0.00-3.25^{a}$ & $(0.00,6.43)$ \\
\hline
\end{tabular}

$a$ : according to age group; CI: confidence interval 
The results point to the conclusion that dried blood spots are simple and inexpensive tool for the surveillance of many infectious diseases in countries with an established Neonatal Screening Network, such as Brazil. It may also become a practical surveillance strategy, albeit it is still necessary to compare its results in a concomitant study with the usual sentinel methodology to validate it for infectious disease surveillance, as HIV and HCV.

\section{REFERENCES}

Aebischer ML, Martorana MC, Costa F, Battaggia C, Madera A, Destito D, Machera F, Bailly C, Angeloni P 1990. Evaluation of the sensitivity of microfilter paper assays in an anthropological study: results of samples from Cameroon and Tanzania. Anthropol Anz 48: 15-23.

Alary M, Castel J 1990. Risk factors for HIV seropositivity among people consulting for HIV antibody testing: a pilot surveillance study in Quebec. CMAJ 143: 25-31.

Alary M, Joly JR, Parent R, Fauvel M, Dionne M 1994. Sentinel hospital surveillance of HIV infection in Quebec. Quebec Sentinel Hospital HIV-Seroprevalence Study Group. CMAJ 151: 975-981.

Amar HS, Ho JJ, Mohan AJ 1999. Human immunodeficiency virus prevalence in women at delivery using unlinked anonymous testing of newborns in the Malaysian setting. J Paediatr Child Health 35: 63-66.

Beck IA, Drennan KD, Melvin AJ, Mohan KM, Herz AM, Alarcon J, Piscoya J, Velazquez C, Frenkel LM 2001. Simple, sensitive, and specific detection of human immunodeficiency virus type 1 subtype B DNA in dried blood samples for diagnosis in infants in the field. J Clin Microbiol 39: 29-33.

Biggar RJ, Miley W, Miotti P, Taha TE, Butcher A, Spadoro J, Waters D 1997. Blood collection on filter paper: a practical approach to sample collection for studies of perinatal HIV transmission. J Acquir Immune Defic Syndr Hum Retrovirol 14: 368-373.

Borgdorff M, Barongo L, van Jaarsveld E, Klokke A, Senkoro K, Newell J, Nicoll A, Mosha F, Grosskurth H, Swai R 1993. Sentinel surveillance for HIV-1 infection: how representative are blood donors, outpatients with fever, anaemia, or sexually transmitted diseases, and antenatal clinic attendees in Mwanza Region, Tanzania? AIDS 7: 567-572.

Canosa CA, Grady GF, Cabello ML, Comeau AM, Schwerzler ME, Contreras MT, Fraga JM, Gomez de los Terreros I, Pena J 1997. Anonymous testing of newborn infants for HIV antibodies as a basis for estimating prevalence of HIV in childbearing women: the 1991-1994 study in Spain. Acta Paediatr (Suppl.) 421: 67-71.

Cassol S, Salas T, Arella M, Neumann P, Schechter MT, O’Shaughnessy M 1991. Use of dried blood spot specimens in the detection of human immunodeficiency virus type 1 by the polymerase chain reaction. J Clin Microbiol 29: 667-671.

Cassol S, Salas T, Gill MJ, Montpetit M, Rudnik J, Sy CT, O'Shaughnessy MV 1992. Stability of dried blood spot specimens for detection of human immunodeficiency virus DNA by polymerase chain reaction. J Clin Microbiol 30: 3039-3042.

Comeau AM, Pitt J, Hillyer GV, Landesman S, Bremer J, Chang
BH, Lew J, Moye J, Grady GF, McIntosh K 1996. Early detection of human immunodeficiency virus on dried blood spot specimens: sensitivity across serial specimens. Women and Infants Transmission Study Group. J Pediatr 129: 111118.

Dondero Jr. TJ, Pappaioanou M, Curran JW 1988. Monitoring the levels and trends of HIV infection: the Public Health Service's HIV surveillance program. Public Health Rep 103: 213-220.

Focaccia R, da Conceição OJ, Sette Jr. H, Sabino E, Bassit L, Nitrini DR, Lomar AV, Lorenço R, Vieira De Souza F, Kiffer CR, Santos EB, Gonzales MP, Saez-Alquezar A, Riscal JR, Fischer D 1998. Estimated prevalence of viral hepatitis in the general population of the municipality of São Paulo, measured by a serologic survey of a stratified, randomized and residence-based population. Braz J Infect Dis 2: 269284.

Gascon J, Bruguera M, Corachan M, Mayor A, Sanchez Tapias JM, Rodes J 1988. Serological survey of hepatitis B in Northern Rwanda. Trop Geogr Med 40: 293-297.

Gupta BP, Jayasuryan N, Jameel S 1992. Direct detection of hepatitis B virus from dried blood spots by polymerase chain reaction amplification. J Clin Microbiol 30: 19131916.

Gwinn M, Pappaioanou M, George JR, Hannon WH, Wasser SC, Redus MA, Hoff R, Grady GF, Willoughby A, Novello AC 1991. Prevalence of HIV infection in childbearing women in the United States. Surveillance using newborn blood samples. JAMA 265: 1704-1708.

Kigadye RM, Klokke A, Nicoll A, Nyamuryekung'e KM, Borgdorff M, Barongo L, Laukamm-Josten U, Lisekie F, Grosskurth H, Kigadye F 1993. Sentinel surveillance for HIV-1 among pregnant women in a developing country: 3 years' experience and comparison with a population serosurvey. AIDS 7: 849-855.

Lemeshow S, Hosmer D, Klar J, Lwanga S 1990. Adequacy of Sample Size in Health Studies, John Wiley, New York, 252 pp.

Matuszak DL, Panny SR, Patel J, Israel E 1990. HIV antibody seroprevalence among childbearing women surveyed in Maryland. Public Health Rep 105: 562-566.

McLaws ML, Brown AR, Cunningham PH, Imrie AA, Wilcken B, Cooper DA 1990. Prevalence of maternal HIV infection based on anonymous testing of neonates, Sydney 1989. Med J Aust 153: 383-386.

Nyambi PN, Fransen K, De Beenhouwer H, Chomba EN, Temmerman M, Ndinya-Achola JO, Piot P, van der Groen G 1994. Detection of human immunodeficiency virus type 1 (HIV-1) in heel prick blood on filter paper from children born to HIV-1-seropositive mothers. J Clin Microbiol 32: 2858-2860.

Panteleeff DD, John G, Nduati R, Mbori-Ngacha D, Richardson B, Kreiss J, Overbaugh J 1999. Rapid method for screening dried blood samples on filter paper for human immunodeficiency virus type 1 DNA. J Clin Microbiol 37: 350-353.

Pappaioanou M, George JR, Hannon WH, Gwinn M, Dondero Jr. TJ, Grady GF, Hoff R, Willoughby AD, Wright A, Novello AC 1990. HIV seroprevalence surveys of childbearing women - objectives, methods, and uses of the data. Public Health Rep 105: 147-152. 
Pappaioanou M, Kashamuka M, Behets F, Mbala S, Biyela K, Davachi F, George JR, Green TA, Dondero TJ, Heyward WL 1993. Accurate detection of maternal antibodies to HIV in newborn whole blood dried on filter paper. AIDS 7: 483488.

Parker SP, Khan HI, Cubitt WD 1999. Detection of antibodies to hepatitis $\mathrm{C}$ virus in dried blood spot samples from mothers and their offspring in Lahore, Pakistan. J Clin Microbiol 37: 2061-2063.

Parry JV, Mortimer PP, Nicoll AG 1992. Performance assessment of neonatal dried blood spot testing for HIV antibody. Commun Dis Rep CDR Rev 2: R128-130.

Proietti A, Gonçalves V, Eller R 2001. Padronização dos testes sorológicos. In Projeto AJUDE-Brasil: Avaliação Epidemiológica dos Usuários de Drogas Injetáveis dos Projetos de Redução de Danos (PRD) Apoiados pela CNDST/Aids, Ministério da Saúde, Brasília, p. 37-51.

Rollins NC, Dedicoat M, Danaviah S, Page T, Bishop K, Kleinschmidt I, Coovadia HM, Cassol SA 2002. Prevalence, incidence, and mother-to-child transmission of HIV1 in rural South Africa. Lancet 360: 389.

Rosner B 1995. Fundamentals of Biostatistics, 4th. ed, Duxbury, New York.

Serjeant GR 2000. Screening for sickle-cell disease in Brazil. Lancet 356: 168-169.

Siedler A, Hamouda O, Schwartlander B 1998. Anonymous unlinked testing as a sentinel approach: experience in Germany. J Epidemiol Community Health 52 (Suppl.) 1: 25S$27 \mathrm{~S}$.

Singh J, Bhatia R, Khare S, Patnaik SK, Biswas S, Lal S, Jain DC, Sokhey J 2000. Community studies on prevalence of HBsAg in two urban populations of southern India. Indian Pediatr 37: 149-152.

Szwarcwald CL, Castilho EA 2000. Estimativa do número de pessoas de 15 a 49 anos infectadas pelo HIV, Brasil, 1998. Cad Saúde Pública 16: 135-141.

Tappin DM, Girdwood RW, Follett EA, Kennedy R, Brown AJ, Cockburn F 1991. Prevalence of maternal HIV infection in Scotland based on unlinked anonymous testing of newborn babies. Lancet 337: 1565-1567.

Tappin DM, Greer K, Cameron S, Kennedy R, Brown AJ, Girdwood RW 1998. Maternal antibody to hepatitis B core antigen detected in dried neonatal blood spot samples. Epidemiol Infect 121: 387-390.

Varnier OE, Lillo FB, Reina S, De Maria A, Terragna A, Schito G 1988. Whole blood collection on filter paper is an effective means of obtaining samples for human immunodeficiency virus antibody assay. AIDS Res Hum Retroviruses 4: $131-136$.

WHO 1992. Global programme on AIDS. Recommendations for the selection and use of HIV antibody tests. Wkly Epidemiol Rec 67: 145-149. 